\title{
Oral Mouthrinse to Prevent Ventilator-associated Pneumonia Caused by COVID-19
}

\author{
Bruna Lavinas Sayed Picciani, ${ }^{1,2}$ Maria Eduarda Rocha Condé, ${ }^{3}$ Natalia lorio Lopes Pontes Póvoa, ${ }^{1,3}$ Helvécio Cardoso Corrêa Póvoa ${ }^{3}$ \\ ${ }^{1}$ Postgraduate Program in Dentistry, Health Institute of Nova Friburgo (PPGO-ISNF), Fluminense Federal University (UFF), Nova Friburgo, RJ, Brazil \\ ${ }^{2}$ Postgraduate Program in Pathology, School of Medicine, Fluminense Federal University (UFF), Niterói, RJ, Brazil \\ ${ }^{3}$ Department of Basic Science, Fluminense Federal University (UFF), Nova Friburgo, RJ, Brazil \\ - Conflicts of interest: none declared.
}

\section{Dear Editor,}

I $\mathrm{n}$ the past two decades, coronavirus strains have been the causative agents of two major outbreaks: The Severe Acute Respiratory Syndrome (SARS) reported in 2002, and the Respiratory Syndrome of the Middle East Respiratory (MERS) reported in 2012. In December 2019, a new form of viral pneumonia associated with severe respiratory failure emerged in Wuhan, China. In January 2020, the World Health Organization issued an alert relating to a new viral epidemic caused by Severe Acute Respiratory Syndrome Coronavirus 2 (SARS-CoV-2). This virus has the potential to be transmitted by direct physical contact and directly or indirectly through, saliva droplets. ${ }^{1,2}$ SARS-CoV-2 permeates through human cells by binding their spike protein (S) to either the angiotensin-converting enzyme II (ACE-2) cell receptors present throughout the respiratory tract or the cells morphologically equivalent to salivary gland duct epithelia in the human mouth, which is supported by the host cell protease TMPRSS-2. The increased expression of ACE-2 in humans negatively regulates the renin-angiotensin system, which can result in the development of Acute Respiratory Discomfort Syndrome (ARDS). This syndrome is characterized by interstitial inflammation with alveolar exudation, which reduces the lung surface area and respiratory capacity of the patient, requiring mechanical ventilation for treatment. However, despite the use of artificial ventilation in most of the severe cases, this approach is commonly a gateway for co-infections. ${ }^{3,4}$

Serious complications related to COVID-19 have been reported in some patients. These include ARDS, acute renal failure, septic shock and ventilator-associated pneumonia. Ventilator-Associated Pneumonia (VAP) following virus infection is an important cause of death, requiring early implementation of preventive measures. Biofilm formation, an early and constant process that occurs in the endotracheal tube (ET) used in mechanical ventilation, is due to the growth of bacteria (either pathogenic or non-pathogenic strains) in a glycoprotein matrix. This layer of microorganisms becomes a harbor for the growth and association of several different pathogens such as viruses, fungi and other bacterial strains. Potentially, pathogenic microorganisms found in oropharyngeal secretions reach the lower respiratory tract through the space between the cuff of the ET and the tracheal wall. ${ }^{5}$

VAP caused by multi-drug resistant (MDR) Acinetobacter baumannii, present in biofilm, remains the major cause of high mortality rates in critically ill patients. Also, viral particles can adhere to oral biofilms and have been reported to be present in the saliva of infected individuals. ${ }^{6,7}$ Therefore, it can be expected that SARS-CoV-2 may be present in biofilms formed in the mouth and in the endotracheal tube. Thus, approaches that control microbial growth and biofilm formation in the oral cavity are crucial to prevent Acinetobacter spp. coinfection as well as to minimize the viral load in the patient fluids and the consequent contagious in hospital environments. However, $0.02 \%$ chlorhexidine digluconate, an antiseptic used against a wide variety of bacteria, was basically ineffective against coronavirus. Some A. baumannii strains also demonstrated their resistance to this mouthrinse, due to their ability to actively discharge a protein responsible for disabling the chlorhexidine digluconate. ${ }^{8,9}$

Thus, oral hygiene care is vital for critically ill patients is crucial to prevent ventilator-associated pneumonia associated with MDR A. baumanniinn and other potential pathogenic strains during the Coronavirus pandemic (COVID-19). Mouthrinses containing chlorhexidine digluconate, hydrogen peroxide and povidone-iodine are available to performed this oral hygiene. The oral care with $0.12 \%$ chlorhexidine has been used widely in preventing VAP. ${ }^{10}$ However, some authors showed that chlorhexidine digluconate are less effective against coronavirus. ${ }^{8,11}$ Oxidizing agents, such as hydrogen peroxide (1\%) and povidone-iodine $(0.23 \%)$, showed rapid bactericidal activity and quickly inactivated SARS$\mathrm{CoV}$, MERS-CoV, influenza virus A (H1N1) and rotavirus. These approaches provide protective oropharyngeal hygiene 
measures for individuals at high risk of coinfections with oral and respiratory pathogens. ${ }^{12}$ At the same time that there are no clinical studies supporting the virucidal effects of any preprocedural mouthrinse against SARS$\mathrm{CoV}-2$ and active substances present in mouthrinse can be not active against pathogens as well as present detrimental effects to its users. Due to the limited data available on the microbiological epidemiology (and the prevalence of antimicrobial resistance) of bacterial superinfections in patients with COVID-19, it is difficult to provide specific pathogen-oriented recommendations..$^{13}$ Therefore, pending further studies, antimicrobial prophylaxis should be prescribed rationally COVID-19 patients according to their clinical syndrome, choosing the most suited antimicrobial agents based on local guidelines and local antibiotic susceptibility patterns, with early deescalation or discontinuation according to microbiology results, whenever available. The COVID-19 pandemic is still ongoing. Moreover, there is still no consensus in the literature regarding which antiseptic solution to use for oral hygiene of these patients with COVID. Further investigation into the most useful preprocedural mouthrinse is warranted especially to avoid VAP by MDR $A$. baumanni in these patients.

\section{References}

1. Wit E, Van Doremalen N, Falzarano D, Munster VJ. SARS and MERS: recent insights into emerging coronaviruses. Nat Rev Microbiol.2016;14:523-34.

2. Xu H, Zhong L, Deng J, Peng J, Dan H, Zeng X, et al. High expression of ACE2 receptor of 2019-nCoV on the epithelial cells of oral mucosa. Int J Oral Sci. 2020;12:1-5.

3. Zhao Y, Zhao Z, Wang Y, Zhou Y, Ma Y, Zuo W. Single-cell RNA expression profiling of ACE2, the putative receptor of Wuhan 2019-nCov. BioRxiv Preprints. 2020.

4. Zhou P, Yang XL, Wang XG, Hu B, Zhang L, Zhang W, et al. A pneumonia outbreak associated with a new coronavirus of probable bat origin. Nature. 2020;579:270-3.

5. Al-Quteimat OM, Amer AM. SARS-CoV-2 outbreak: How can pharmacists help? Res Social Adm Pharm. 2020;7411:30238-42.

6. Moubareck AC, Halat DH. Insights into Acinetobacter baumannii: A Review of Microbiological, Virulence, and Resistance Traits in a Threatening Nosocomial Pathogen. Antibiotics. 2020;9:119.

7. To KKW, Tsang OTY, Yip CCY, Chan KH, Wu TC, Chan JMC, et al.

Consistent detection of 2019 novel coronavirus in saliva. Clin Infect Dis. 2020;12:149.

8. Kampf G, Todt D, Pfaender S, Steinmann E. Persistence of coronaviruses on inanimate surfaces and its inactivation with biocidal agents. J Hosp Infect. 2020;104:246-51.

9. Hassan KA, Jackson SM, Penesyan A, Patching SG, Tetu SG, Eijkelkamp $\mathrm{BA}$, et al. Transcriptomic and biochemical analyses identify a family of chlorhexidine efflux proteins. Proc Natl Acad Sci U S A. 2013;110:20254-9.

10. Munro N, Ruggiero M. Ventilator-associated pneumonia bundle. AACN Adv Crit Care. 2014;25:163-75.

11. Wood A, Payne D. The action of three antiseptics/disinfectants against enveloped and non-enveloped viruses. J Hosp Infect. 1998;38:283-95.

12. Peng X, Xu X, Li Y, Cheng L, Zhou X, Ren B. Transmission routes of 2019$\mathrm{nCoV}$ and controls in dental practice. Int J Oral Sci. 2020;12:1-6.

13. Ortega KL, Camargo AR, Franco JB, Azul AM, Sayáns MP, Silva PHB. SARS-CoV-2 and dentistry. Clin Oral Investig. 2020;5:1-2.

\section{Mini Curriculum and Author's Contribution}

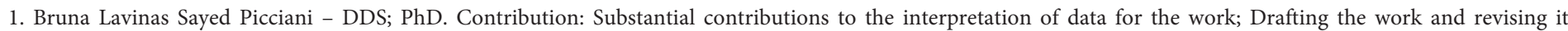
critically for important intellectual content; Final approval of the version to be published. ORCID: 0000-0001-7592-1785

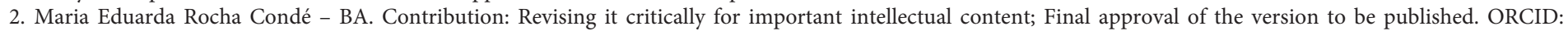
0000-0002-0368-0377

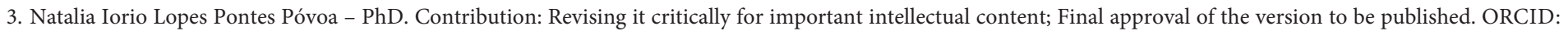
0000-0001-5339-534X

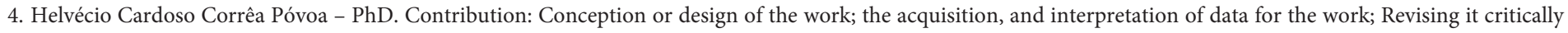
for important intellectual content; Final approval of the version to be published. ORCID: 0000-0002-2759-2216

Submitted: 10/29/2020 / Accepted for publication: 12/08/2020

Corresponding author:

Helvécio Cardoso Corrêa Póvoa

E-mail: helveciopovoa@gmail.com 